\title{
Cytokines in haemolytic uraemic syndrome associated with verocytotoxin-producing Escherichia coli infection
}

\author{
C D Inward, M Varagunam, D Adu, D V Milford, C M Taylor
}

\begin{abstract}
The proinflammatory cytokines tumour necrosis factor- $\alpha$ (TNF- $\alpha)$, interleukin (IL)-1ß, IL-6, and IL-8 were measured in plasma and urine samples from 19 children with verocytotoxin-producing $E s$ cherichia coli (VTEC) induced haemolytic uraemic syndrome (HUS) and 30 controls. TNF- $\alpha$ was detected in the plasma of two cases and one control; IL-6 in the plasma of one, and the urine of two cases, and in

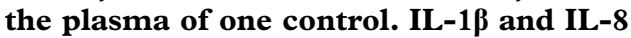
were each identified in eight of the 19 cases and in one and two controls respectively. Urinary IL-8 was found in seven cases, four of whom had plasma concentrations below the limit of detection suggesting renal secretion of this cytokine. Cytokine concentrations did not correlate with peripheral blood neutrophil count at onset of disease. These data confirm the systemic release of cytokines responsible for the coordination of acute inflammatory processes in some children with VTEC induced HUS.

(Arch Dis Child 1997;77:145-147)
\end{abstract}

Keywords: cytokines; haemolytic uraemic syndrome; verocytotoxin-producing Escherichia coli

Haemolytic uraemic syndrome (HUS) is recognised as acute renal failure in the presence of microangiopathic haemolytic anaemia and thrombocytopenia. Although there are many causes, the syndrome can be broadly divided into two types depending upon the presence or absence of prodromal diarrhoea. The latter is currently the commonest form of acute renal failure in childhood. The epidemiological link between diarrhoea associated HUS (D+HUS) and infection with verocytotoxin-producing Escherichia coli (VTEC) is well known. However, details of pathogenesis remain speculative. It is assumed that verocytotoxin itself plays an important part. In vitro studies have shown that verocytotoxin is lethal to a range of primate cells in culture and, at least in verocells, the mode of cell death is apoptosis. ${ }^{1}$ The human kidney has receptors for this toxin and it is of note that cultured human umbilical vein endothelial cells are rendered more susceptible to verocytotoxin in the presence of proinflammatory cytokines tumour necrosis factor- $\alpha(\mathrm{TNF}-\alpha)$ and interleukin (IL) $-1 \beta .^{2}$

There is clinical evidence of an acute inflammatory response in VTEC infection. Specifi- cally, neutrophilia occurs in the few days after onset of diarrhoea and the magnitude of this response correlates with the development of HUS $^{3}$ and poor outcome. ${ }^{4}$ We therefore measured the cytokines responsible for coordinating acute inflammation, TNF- $\alpha$, IL $1 \beta$, IL- 6 , and IL- 8 , in the plasma and urine of a group of children with acute haemolytic uraemic syndrome associated with VTEC infection.

\section{Patients and methods}

The following groups of children were studied:

Group 1: Plasma samples were collected from a series of 19 children presenting to the Birmingham Children's Hospital with acute HUS (median age 3.3 years, range 0.8-11.6). Urine was collected on admission or as soon as a diuresis began in 11 of these. Blood was taken on admission before any renal replacement treatment or transfusion. Thirteen of the children in this group required peritoneal dialysis. Infection with VTEC 0157 was confirmed by stool culture or serology in all cases.

Group 2: Blood and urine was obtained from nine children with a past history of D+HUS followed up at the same centre (median age 6.1 years, range 1.3-12.8). The median time from diagnosis of the acute illness was 5.0 years (range $0.5-10.0$ years). Six of these children received peritoneal dialysis.

Group 3: Blood samples were collected from 11 children with chronic renal failure (median age 12.5 years, range $2.8-17.0$ ). This was a group of predialysis patients who had had congenital renal dysplasia or reflux nephropathy as the cause of their renal impairment. They had a median glomerular filtration rate of 28 $\mathrm{ml} / \mathrm{min} / 1.73 \mathrm{~m}$ (range 10-50) estimated from their height and plasma creatinine concentration. Plasma samples only were collected from this group. There was no clinical evidence of infection at the time of sampling.

Group 4: Blood samples were obtained from 10 healthy children (median age 6.3 years, range 2.0-14.6) who were undergoing minor surgical procedures. Urine was collected from eight of these.

Ethical committee approval was granted for collection of the samples.

SAMPLE HANDLING

Plasma samples were collected in EDTA with a proteinase inhibitor (aprotinin $50 \mathrm{KIU} / 5 \mathrm{ml}$ sample), centrifuged at $3000 \mathrm{rpm}$ for 10 
Table 1 White cell and neutrophil counts and plasma creatinine in the four groups (for definition of groups see patients and methods); results are median (range)

\begin{tabular}{|c|c|c|c|c|}
\hline & Group 1 & Group 2 & Group 3 & Group 4 \\
\hline White cell count $\left(\times 10^{9} / 1\right)$ & $14.5(7.8-43.1)$ & $\begin{array}{l}7.9(5.0-20.2) \\
p=0.004\end{array}$ & $\begin{array}{l}7.1(4.4-20.5) \\
\mathrm{p}=0.0002\end{array}$ & $\begin{array}{l}8.9(5.7-10.8) \\
p=0.01\end{array}$ \\
\hline Neutrophil count $\left(\times 10^{9} / 1\right)$ & $10.1(4.3-26.5)$ & $\begin{array}{l}4.2(2.1-8.7) \\
\mathrm{p}=0.002\end{array}$ & $\begin{array}{l}2.3(1.4-10.3) \\
\mathrm{p}=0.01\end{array}$ & $\begin{array}{l}4.3(3.7-6.6) \\
p=0.008\end{array}$ \\
\hline Creatinine $(\mathrm{mmol} / \mathrm{l})$ & $416(74-1046)$ & $\begin{array}{l}55(25-84) \\
\mathrm{p}=0.0002\end{array}$ & $\begin{array}{l}160(46-1080) \\
p=N S\end{array}$ & $\begin{array}{l}52(41-69) \\
\mathrm{p}=0.0014\end{array}$ \\
\hline
\end{tabular}

minutes within two hours of collection and then stored immediately at $-70^{\circ} \mathrm{C}$ until assayed.

Urine samples were collected and sent to the laboratory in plain universal containers. They were centrifuged at $3000 \mathrm{rpm}$ for 10 minutes to remove cells and sediment. Samples were frozen within two hours of collection and stored at $-70^{\circ} \mathrm{C}$ until assayed.

CYTOKINE ASSAYS

Cytokines were measured using sandwich enzyme linked immunosorbent assays (ELISAs) developed according to the method specified in the World Health Organisation Bench Manual for the Preparation of Immunological and Immuno-diagnostic Reagent. Microtitre plates were coated with monoclonal antibody overnight at $4^{\circ} \mathrm{C}$. The concentrations of antibody were as follows: anti-TNF- $\alpha$ (Celltech) $10 \mathrm{mg} / \mathrm{ml}$; anti-IL-8 (Serotec) $2.5 \mathrm{mg} / \mathrm{ml}$. Serial incubations were then performed at $37^{\circ} \mathrm{C}$ for one hour as follows:

(1) Sample or standard, recombinant human cytokine (R\&D Systems Europe) was used to construct a standard curve on each plate.

(2) Goat anticytokine polyclonal antibody (R\&D Systems Europe) $2 \mathrm{mg} / \mathrm{ml}$ in $2 \%$ mouse serum.

(3) Donkey antigoat horseradish peroxidase (Binding Site) diluted 1:20 000 in 2\% mouse serum.

All dilutions were made in phosphate buffered saline (PBS)-Tween and washes were carried out after each incubation using PBSTween. A colour reaction was developed by incubation with $o$-phenylenediamine dihydrochloride in citrate buffer and the reaction stopped using $20 \%$ sulphuric acid. The optical density was read at $492 \mathrm{~nm}$ and the concentration of cytokine in the sample determined from the standard curve. Samples and standards were assayed in duplicate. The lower limit of detection of these assays was $625 \mathrm{pg} / \mathrm{ml}$; interassay variation for the different cytokines ranged from $11.8-13.2 \%$, and intra-assay variation from 5.5 to $6.3 \%$. Urinary protein was measured by Coomassie blue dye binding technique, and urine creatinine by autoanalyser in the same samples used for cytokine assay.

\section{Results}

The total white cell count, neutrophil count, and plasma creatinine for each of the groups studied is shown in table $1 ; \mathrm{p}$ values refer to differences between children with acute VTEC associated HUS and the other groups (Wilcoxon rank sum test).
CYTOKINES

TNF- $\alpha$ was present in the plasma of two children with acute HUS (group 1) at concentrations of $6250,6800 \mathrm{pg} / \mathrm{ml}$, and in one child with chronic renal failure (group 3) at 17000 $\mathrm{pg} / \mathrm{ml}$. No TNF- $\alpha$ was detected in any of the urine samples. IL-1 $\beta$ was detected in the plasma of eight children in group 1: median $2250 \mathrm{pg} / \mathrm{ml}$, range 1200-10 900 and one child in group 3: $8670 \mathrm{pg} / \mathrm{ml}$. No IL-1 $\beta$ was detected in any of the urine samples.

IL-6 was present in one child in group 1 at a plasma concentration of $650 \mathrm{pg} / \mathrm{ml}$ and in one patient in group 3 at $660 \mathrm{pg} / \mathrm{ml}$. IL-6 was detected in the urine of two children with acute HUS at 1560 and $2550 \mathrm{pg} / \mathrm{ml}$ respectively. IL-8 was detected in the plasma of eight children from group 1: median $1070 \mathrm{pg} / \mathrm{ml}$, range 625-80 000 and in two children from group 3: 860 and $6700 \mathrm{pg} / \mathrm{ml}$. IL-8 was present in the urine of seven children with acute HUS: median $2440 \mathrm{pg} / \mathrm{ml}$, range 850-8270. In four of these IL-8 could not be detected in plasma.

Those subjects in whom TNF- $\alpha$ was detected had the highest plasma concentrations of IL- $1 \beta$ and also tended to have high concentrations of IL-8. In children with acute HUS there was no correlation between plasma or urine cytokines and the peripheral blood neutrophil count at onset, and no correlation between urine cytokines and urine protein or creatinine concentration. No cytokines were detected in the plasma or urine of children with either a past history of D+HUS (group 2) or in the healthy controls (group 4).

\section{Discussion}

The pattern of cytokine secretion during HUS is beginning to emerge. In this study we have shown that a systemic proinflammatory cytokine response occurs in some children during the course of VTEC induced HUS. The predominant cytokines we found were IL- $1 \beta$ and IL-8. TNF- $\alpha$ was present in the plasma of just two out of 19 children with acute HUS, and in one of the chronic renal failure controls. Plasma IL-6 was detected in one patient in our study. This was the only child to exhibit extrarenal manifestations of the syndrome; the patient died of central nervous system disease. Additionally, we have shown that IL-8 is present in the urine and that urinary concentrations were higher than that of plasma. Moreover IL-8 was detected in the urine of four patients who had no detectable plasma IL-8, suggesting that this cytokine may have been produced in the kidney itself. We found no correlation between plasma or urine IL-8 and either the actual clinical outcome or the 
initial neutrophil count, which has been shown previously to correlate with outcome. This may be explained both by the small number of patients in our study and because apart from the one neurological death all patients recovered quickly from their renal disease. Also we acknowledge that our ELISA for these cytokines was relatively insensitive at low concentrations.

Other groups have investigated the role of cytokines in HUS. Van de Kar et al showed no increase in plasma TNF- $\alpha$ compared with healthy controls, ${ }^{6}$ while Fitzpatrick et al found $\mathrm{TNF}-\alpha$ present in the plasma of only one out of 16 patients and in one of the controls. ${ }^{7}$ Karpman et al identified TNF- $\alpha$ in the plasma of a fifth of children with HUS, and in the urine samples from all of four cases. ${ }^{8}$ A criticism of our paper and these previous reports is that children were not studied during the diarrhoeal prodrome before the diagnosis of HUS was made, so that early events may have been missed. In acute inflammatory conditions TNF- $\alpha$ secretion occurs early and is of short duration. However, Lopez et al investigated plasma TNF- $\alpha$ concentration not only in children with HUS but also in those with bloody diarrhoea. ${ }^{9}$ They found that plasma TNF- $\alpha$ was increased in the first 10 days after the onset of bloody diarrhoea. Most children with HUS present 4-7 days after the onset of the diarrhoeal prodrome and it is possible that we have missed the expression of TNF- $\alpha$ in our VTEC infected subjects.

In the studies of Karpman et al IL-6 was found in the sera of 33 of 35 children with HUS and the concentrations were higher in those who became anuric or exhibited extrarenal manifestations of the syndrome. ${ }^{8}$ The one patient in whom we identified an increased plasma IL- 6 was the only child in our series to have extrarenal manifestations and died from neurological complications. Like Karpman et al we found that the concentration of IL- 6 in urine exceeds that of plasma. While this is compatible with the concept that cytokines are produced in the urinary tract, one should record that the molecular weight of this cytokine is $26 \mathrm{kD}$ and one might expect plasma IL- 6 to be filtered at the glomerulus. The final urine concentration will depend upon catabolism of the cytokine in the tubule on the one hand and reabsorption of filtered saline on the other. A similar proviso needs to be applied in considering the urinary measurement of IL-8.

We confirm previous reports of increased plasma IL-8 concentrations in HUS. Additionally high concentrations were found in the urine. IL-8 is an important neutrophil chemotaxin produced by a wide variety of tissues including endothelial, epithelial, and mesangial cells as well as by neutrophils and monocytes. Not only is it a chemoattractant but it has an important role in priming neutrophils to increase their oxygen radical release when triggered by other stimuli such as platelet activating factor. ${ }^{10}$ IL- 8 is important in many models of inflammation in which neutrophils play a part. For example in a model of immune complex nephritis in rats, blockade of IL-8 with an antibody could reduce the neutrophil infiltration of glomeruli and prevent the development of proteinuria. ${ }^{11}$ Neutrophils appear to have a role in the pathogenesis of VTEC induced HUS. Parvia et al showed that neutrophilia heralded the development of HUS in individuals infected with VTEC. ${ }^{3}$ We and others confirm that the outcome of patients with HUS correlated with the neutrophil count at presentation, ${ }^{45}$ more recently in a collaborative study by the British Association for Paediatric Nephrologists, where necropsies from children with diarrhoea associated HUS had an increased number of neutrophils in their glomeruli compared with controls. ${ }^{12}$ Fitzpatrick et al found that the highest plasma IL-8 concentrations in their study occurred in children who died in the acute phase of their disease. ${ }^{7}$ However, no statistical correlation has been made between neutrophil count at onset and cytokine concentration. The failure of our study to find a correlation may be explained in part by the low sensitivity of our assay and the small numbers of children with an elevated neutrophil count.

In summary cytokines which coordinate the acute inflammatory cascade of events are present in some children with VTEC induced HUS. This may have importance in regulating the traffic of neutrophils into the glomerulus as well as coordinating changes in endothelial function which promote coagulation and thus the distinctive glomerular thrombus of this form of HUS.

Dr M Varagunam was supported by the National Kidney Research Fund and Dr Carol Inward by the Renal Research Fund of the Birmingham Children's Hospital.

1 Inward CD, Williams J, Chant I, et al. Verocytotoxin-1 induces apoptosis in verocells. F Infect 1995;30:213-8.

2 Louise CB, Obrig TG. Shiga toxin-associated hemolytic uremic syndrome: combined cytotoxic effects of Shiga toxin, interleukin-1 $\beta$, and tumour necrosis factor alpha on human vascular endothelial cells in vitro. Infect Immun 1991;59:4173-9.

3 Parvia AT, Nichols CR, Green DP, et al. Hemolytic uremic syndrome during an outbreak of Escherichia coli 0157:H7 infection in institutions for mentally retarded persons: infection in institutions for mentally retarded persons: 116:544-51

4 Walters MS, Matthei IU, Kay R, Dillon MJ, Barratt TM. The polymorphonuclear leucocyte count in childhood hemolytic uremic syndrome. Pediatr Nephrol 1989;3:130-4.

5 Coad NAG, Marshall T, Rowe B, Taylor CM. Changes in the postenteropathic form of the hemolytic uremic syndrome in children. Clin Nephrol 1991;35:10-6.

6 Van de Kar NCAJ, Sauerwein RW, Demacker PNM, Grau GE, van Hinsbergh VWM, Monnens LAH. Plasma cytokine levels in hemolytic uremic syndrome. Nephron 1995;71:309-13.

7 Fitzpatrick MM, Shah V, Trompeter RS, Dillon MJ, Barratt TM. Interleukin-8 and polymorphonuclear leucocyte activation in hemolytic uremic syndrome. Kidney Int 1992;42: 951-6.

8 Karpman D, Andreasson A, Thysell H, Kaplan BS, Svanborg C. Cytokines in childhood hemolytic uremic syndrome and thrombotic thrombocytopenic purpura. Pediatr Nephrol 1995;9:694-9.

9 Lopez EL, Contrini MM, Devoto S, et al. Tumor necrosis factor concentrations in hemolytic uremic syndrome patients and children with bloody diarrhea in Argentina. Pediatr Infect Dis $\mathcal{F}$ 1995;14:594-8.

10 Wozniak A, Betts WH, Murphy GA, Rokicinski M. Interleukin-8 primes human neutrophils for enhanced superoxide anion production. Immunology 1993;79:608-15.

11 Wada T, Tomosugi N, Naito T, et al. Prevention of proteinuria by the administration of anti-interleukin 8 antibody in experimental acute immune lonephritis. F Exp Med 1994;180:1135-40.

12 Inward CD, Howie AJ, Fitzpatrick MM, Rafaat F, Milford DV, Taylor CM. Pediatr Nephrol (in press). 